\title{
Cardiac Metastasis in a Patient with Head and Neck Cancer: A Case Report and Review of the Literature
}

\author{
Joseph K. Kim $\mathbb{D}^{1},{ }^{1}$ Kunal Sindhu $\mathbb{D}^{2}{ }^{2}$ and Richard L. Bakst $\mathbb{D D}^{2}$ \\ ${ }^{1}$ SUNY Downstate Medical Center, Department of Radiation Oncology, Brooklyn, New York, USA \\ ${ }^{2}$ Mount Sinai Medical Center, Department of Radiation Oncology, One Gustave L. Levy Place, Box 1236, New York, \\ New York, USA
}

Correspondence should be addressed to Richard L. Bakst; richard.bakst@mountsinai.org

Received 15 November 2018; Accepted 24 February 2019; Published 18 April 2019

Academic Editor: Abrão Rapoport

Copyright (c) 2019 Joseph K. Kim et al. This is an open access article distributed under the Creative Commons Attribution License, which permits unrestricted use, distribution, and reproduction in any medium, provided the original work is properly cited.

Cardiac metastasis from a primary head and neck cancer is a rare finding. Most patients with cardiac metastases have nonspecific symptoms that may vary depending on the severity and location of the lesion. Due to the infrequency of reported cases, there are no clear guidelines for the diagnosis or management of cardiac metastasis in head and neck cancer patients. In this report, we discuss the case of a patient with a primary diagnosis of oral tongue cancer who developed a cardiac metastasis that was detected antemortem.

\section{Introduction}

Cardiac metastases in patients with head and neck squamous cell carcinoma (HNSCC) are a very rare finding [1]. Most cases of cardiac metastasis are clinically silent with a majority of cases detected in the postmortem setting. If cardiac metastasis is diagnosed in a living patient, the clinical presentation is often variable with nonspecific symptoms. Here, we discuss the clinical presentation, diagnosis, and management of a patient with oral cavity cancer who developed a metastasis to the heart.

\section{Case Presentation}

A 46-year-old white female with a 15 pack-year smoking history initially presented 3 years ago with intense pain in the left side of the mouth that radiated to her left ear for 2 months. She was found to have a $2 \mathrm{~cm}$ exophytic lesion on the left lateral border of her tongue that was diffusely keratotic and extremely tender on examination. Fiberoptic laryngoscopy revealed normal findings in the nasopharynx, oropharynx, and hypopharynx. Histological biopsy of the tongue lesion confirmed well-differentiated squamous cell carcinoma of the left lateral border of the tongue. Radiographical findings on positron emission tomography (PET) scan showed hyperactivity along the left lateral aspect of the tongue and a mildly hypermetabolic left level IIa cervical lymph node with no evidence of distant metastases (Figure 1).

The patient was treated with a left hemiglossectomy and bilateral neck dissection. Pathologic evaluation revealed a $2.4 \mathrm{~cm}$ moderately differentiated, infiltrating squamous cell carcinoma of the left lateral tongue lesion invading into the skeletal muscle with a $0.5 \mathrm{~cm}$ maximal thickness. There was perineural invasion, but no lymphovascular invasion, and all margins were free of cancer. A total of 3 out of 22 lymph nodes were positive for carcinoma: 0 out of 10 in right neck level II-III, 2 out of 5 left level I with no extracapsular extension (ECE), 0 out of 1 left level II, and 1 out of 6 left level III with no ECE.

She was staged as pT2 pN2b M0 (stage IVA, AJCC 7th edition 2010) squamous cell carcinoma of the left lateral tongue. She received adjuvant treatment with concurrent afatinib and radiotherapy to a total dose of $6000 \mathrm{cGy}$ in 30 fractions over 6 weeks to the oral cavity and bilateral necks, which was completed in 3 months after diagnosis.

Interval radiographical imaging did not show any evidence of disease recurrence or distant metastases until 2018. At that time, the patient had developed increasing left arm 


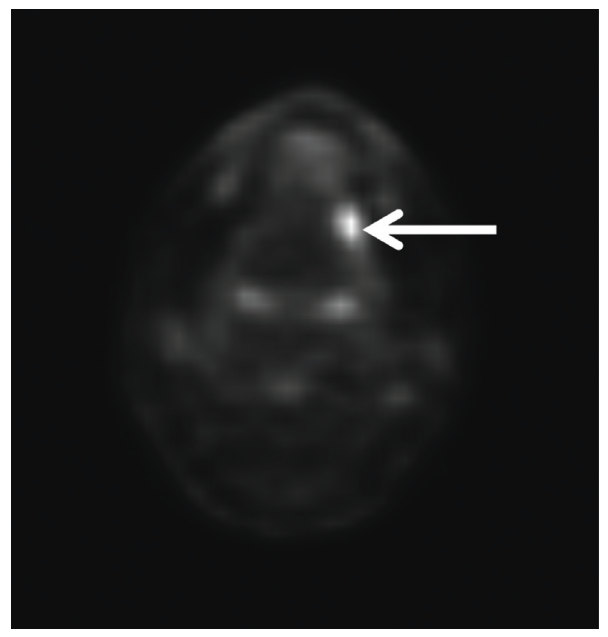

(a)

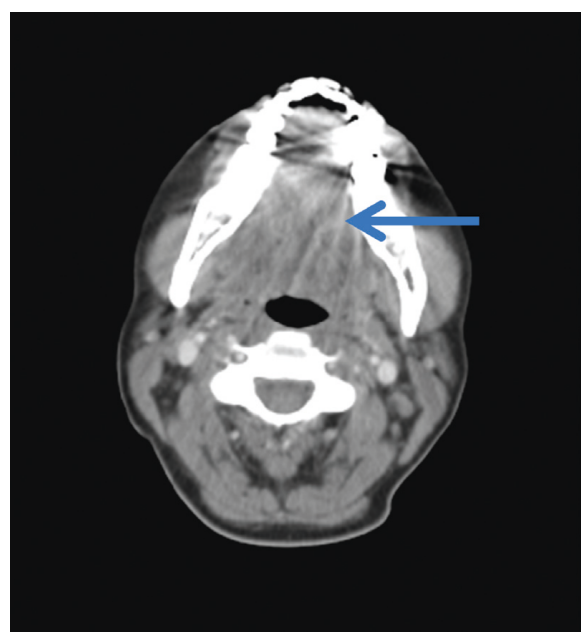

(b)

FIgURE 1: Initial axial PET scan (a) and CT scan (b) demonstrating hyperactivity along the left lateral tongue ((a) white arrow; (b) blue arrow).

pain, left ear pain, and left throat pain. She also reported intermittent chest pressure, exertional dyspnea, and intermittent dizziness with positional changes.

In early 2018, a PET scan (Figure 2) and magnetic resonance imaging (MRI) of the chest (Figure 3) showed a new $3.4 \mathrm{~cm}$ left apical pleural mass encasing the left subclavian artery and abutting the left subclavian vein, both of which were patent. A computed tomography-guided fineneedle aspiration (CT-FNA) of the apical lung mass revealed squamous cell carcinoma.

Shortly after, the patient began systemic therapy with cisplatin and etoposide and radiation therapy to the left apical lung lesion. Following the 20th fraction of radiation therapy, a repeat computed tomography (CT) scan of the chest revealed a new $1.2 \mathrm{~cm}$ lesion in the inferior interventricular septum of the heart. A cardiac ultrasound was performed and demonstrated a mass in the left ventricle. The patient went on to complete radiation therapy to a total of $6000 \mathrm{cGy}$ in 30 fractions. Further diagnostic imaging with a cardiac MRI was performed, which revealed a mass infiltrating the left ventricle, inferior myocardium, epicardial fat, and pericardium with associated mobile thrombus formation (Figure 4). A PET/CT scan demonstrated hypermetabolic lesions in the left neck, right thigh muscles, lung parenchyma, heart, anterior mediastinum, left scapula, and posterior right rib (Figure 2). Transthoracic echocardiogram (TTE) showed a $1.6 \times 1.4 \mathrm{~cm}$ mobile mass in the left ventricle cavity that appeared to be attached to the base of the papillary muscle and a normal left ventricular ejection fraction of $60 \%$. An electrocardiogram (ECG) revealed normal sinus rhythm with $\mathrm{T}$-wave inversion in the inferior leads and $\mathrm{V}_{3}-\mathrm{V}_{6}$.

The patient initiated anticoagulation and systemic therapy with nivolumab.

\section{Discussion}

Cardiac metastases are a rare finding. Since patients are often clinically silent or have nonspecific symptoms, metastases to

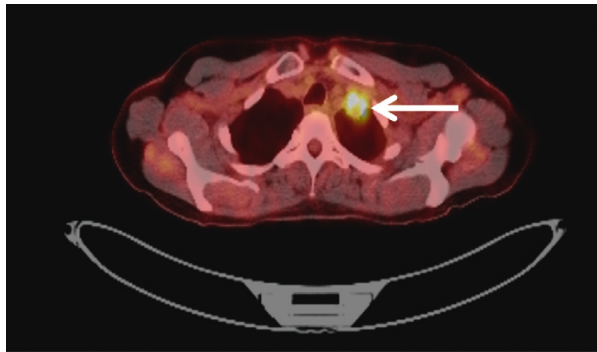

(a)

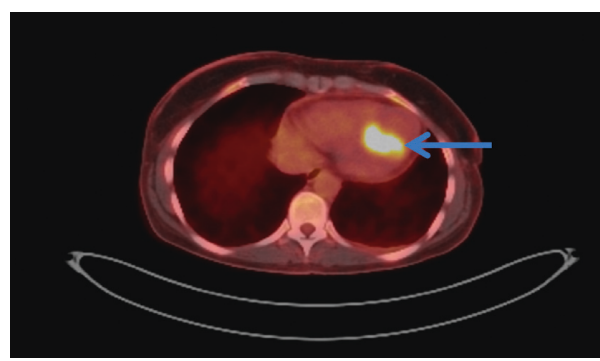

(b)

Figure 2: Axial PET scans revealing a new left apical pleural mass (white arrow) (a) and cardiac metastasis (blue arrow) (b).

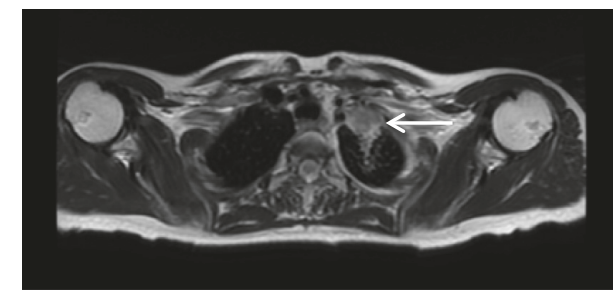

FIGURE 3: MRI of the chest demonstrating a new left apical pleural mass (white arrow).

the heart are difficult to diagnose and usually detected in the postmortem setting during an autopsy. When patients present with symptoms, they can have highly variable 


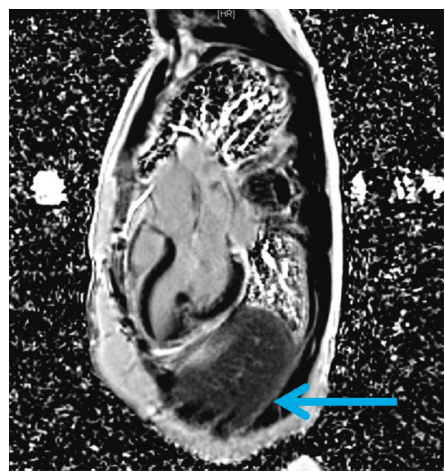

(a)

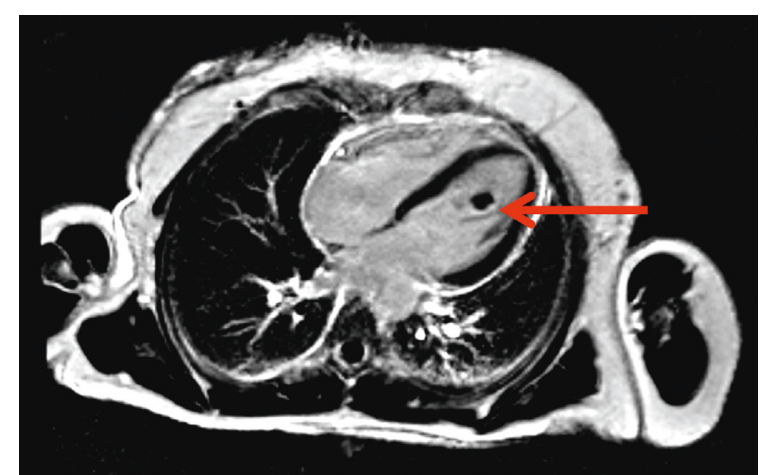

(b)

FIGURE 4: Cardiac MRI demonstrating a new mass infiltrating the left ventricular inferior myocardium, epicardial fat, and pericardium (blue arrow and red arrow).

clinical manifestations, including heart failure, arrhythmias, valvular disease, and cardiac tamponade. The most common primary cancers in patients with cardiac metastases include melanoma, mediastinal tumors, lung cancer, breast cancer, and leukemia [2]. In a large study of postmortem patients with a known malignancy, Bussani et al. reported a 9.1\% overall incidence of cardiac metastases with only 5.3\% (4 out of 75) secondary to oral cavity cancer compared to $48.4 \%$ secondary to mesothelioma, $27.8 \%$ to melanoma, and $21.0 \%$ to lung adenocarcinoma [2]. Four different mechanisms have been postulated by which cancer spreads to the heart, including direct extension, hematologic spread, lymphatic spread, and intracavitary diffusion via the inferior vena cava or pulmonary veins [2-4].

In patients with oral cavity cancer, distant metastases are seen in $4.2-23.8 \%$ of patients, with the lung, bone, and liver as the most commonly involved sites [5]. However, metastatic disease to the heart is highly unusual in patients with oral cavity cancer. The patient in this case report had an especially long duration between primary diagnosis and cardiac metastasis at almost 3 years. In a review of the literature, we found 24 cases of patients with head and neck cancer with cardiac metastases that were detected in the antemortem setting.

Due to the wide range of clinical presentations in patients with cardiac metastases, detection is often incidental. The routine use of imaging is not generally recommended in patients with head and neck cancer to detect metastatic disease unless prompted by clinical signs and symptoms or if the patient is not amenable to clinical examination. Echocardiography is the most frequent noninvasive imaging modality used to evaluate the heart. In our present literature review, echocardiography was the initial imaging modality in more than $50 \%$ of the cases of cardiac metastasis from a primary head and neck cancer (Table 1). Echocardiography allows for assessment of cardiac function, including valvular and ventricular competency, as well as identification of any intraventricular masses or structural wall abnormalities [6]. The diagnostic accuracy of echocardiography has been reported to be as high as $80 \%$, which makes it a good initial method to evaluate suspected cardiac tumors [7]. Other imaging modalities such as CT and MRI may provide a more comprehensive assessment with additional detail, including evaluation of the pericardium and extracardiac disease [8]. Cardiac MRI offers the advantages of excellent contrast resolution and distinction of tumor from the myocardium or thrombus in comparison with CT or ultrasound [9]. MRI also allows for simultaneous assessment of the surrounding structures, including the mediastinum, lungs, and pleura [6]. Particularly in patients with primary tumor of the head and neck, PET/CT may provide additional utility in detecting metastatic disease involving the heart. In a long-term outcome study of PET/CT imaging in head and neck cancer patients treated with definitive or adjuvant radiation therapy, PET/CT had a $99 \%$ negative predictive value in the assessment of the primary site and neck, and negative findings were associated with significantly improved diseasefree survival and overall survival. However, there was a high rate of false-positive results at the primary site, with a positive predictive value of $32.1 \%$ [10]. Therefore, the use of $\mathrm{PET} / \mathrm{CT}$ at 3 months post-RT is generally practiced. Current National Comprehensive Cancer Network (NCCN) guidelines do not recommend the use of routine follow-up imaging unless clinically indicated and no evidence to demonstrate a benefit of surveillance imaging after 6 months [11]. However, multiple case reports have reported that the use of PET/CT may lead to improved accuracy and earlier detection of cardiac metastases in patients with head and neck cancer [4, 12-15]. Some studies have suggested that routine ECG may have a diagnostic value, but findings are often nonspecific, and further confirmation with imaging would be required [15-17]. Table 1 provides a literature review of patients with an antemortem diagnosis of cardiac metastasis from a primary head and neck cancer. In our present study, the patient had already developed metastatic disease in the lung prior to detection of the cardiac metastasis, which was incidentally detected on a review staging CT scan.

There is no standard of care in the treatment of cardiac metastases. Many patients are not surgical candidates due to the location of disease and are treated with palliative chemotherapy and supportive care, but prognosis is often poor. In our present study, the patient initially had presented with metastatic disease to the lung and began treatment with 


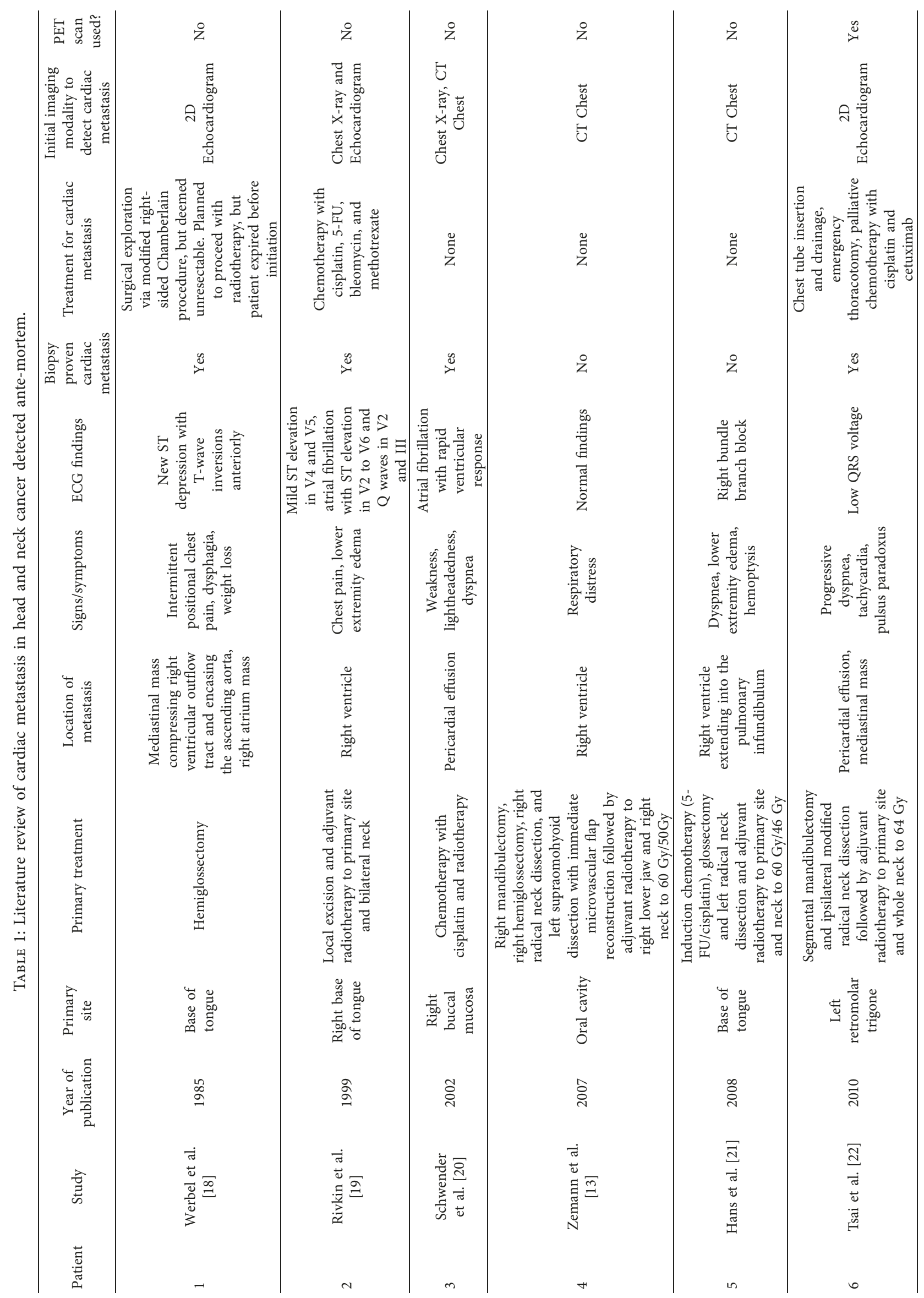




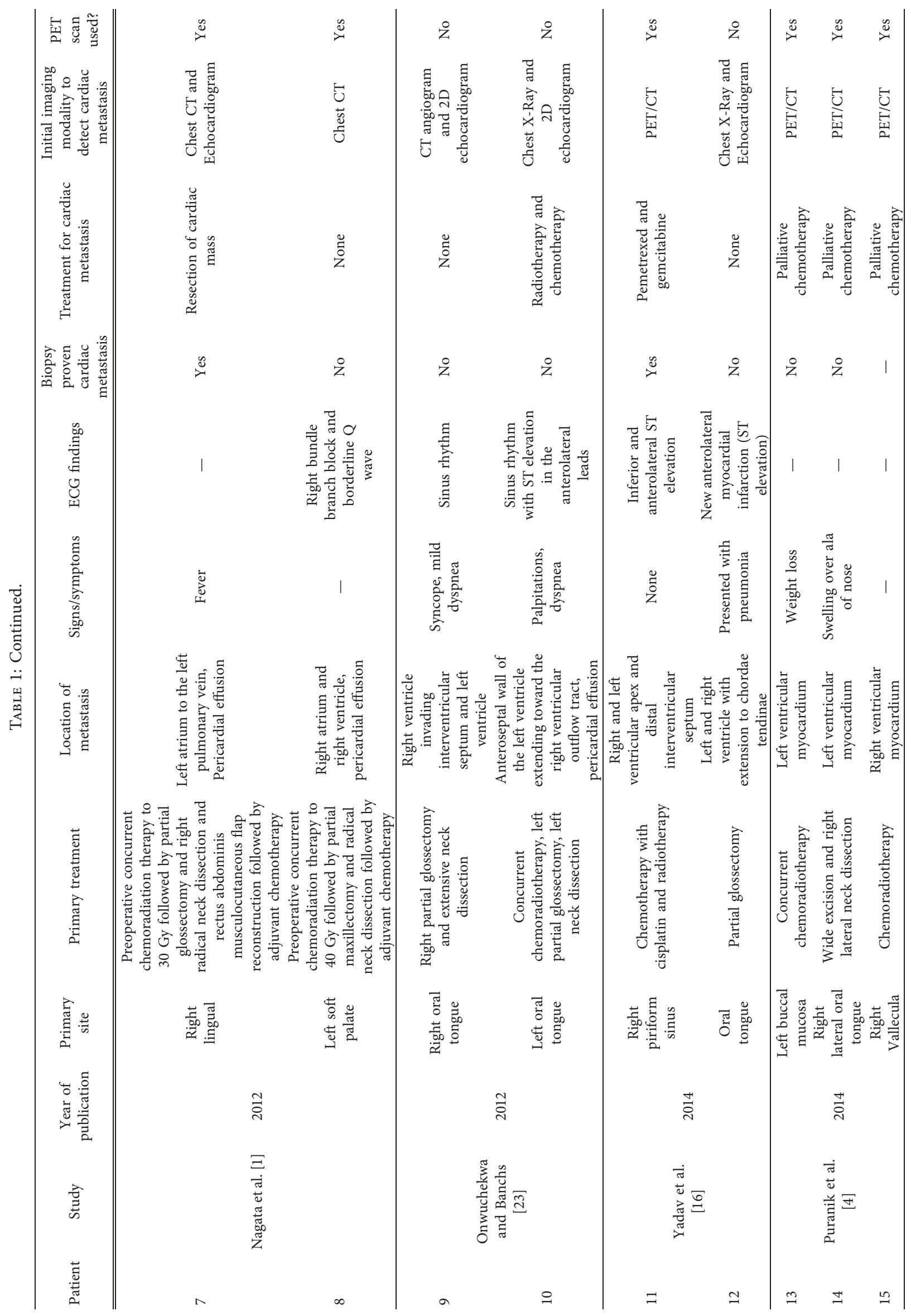




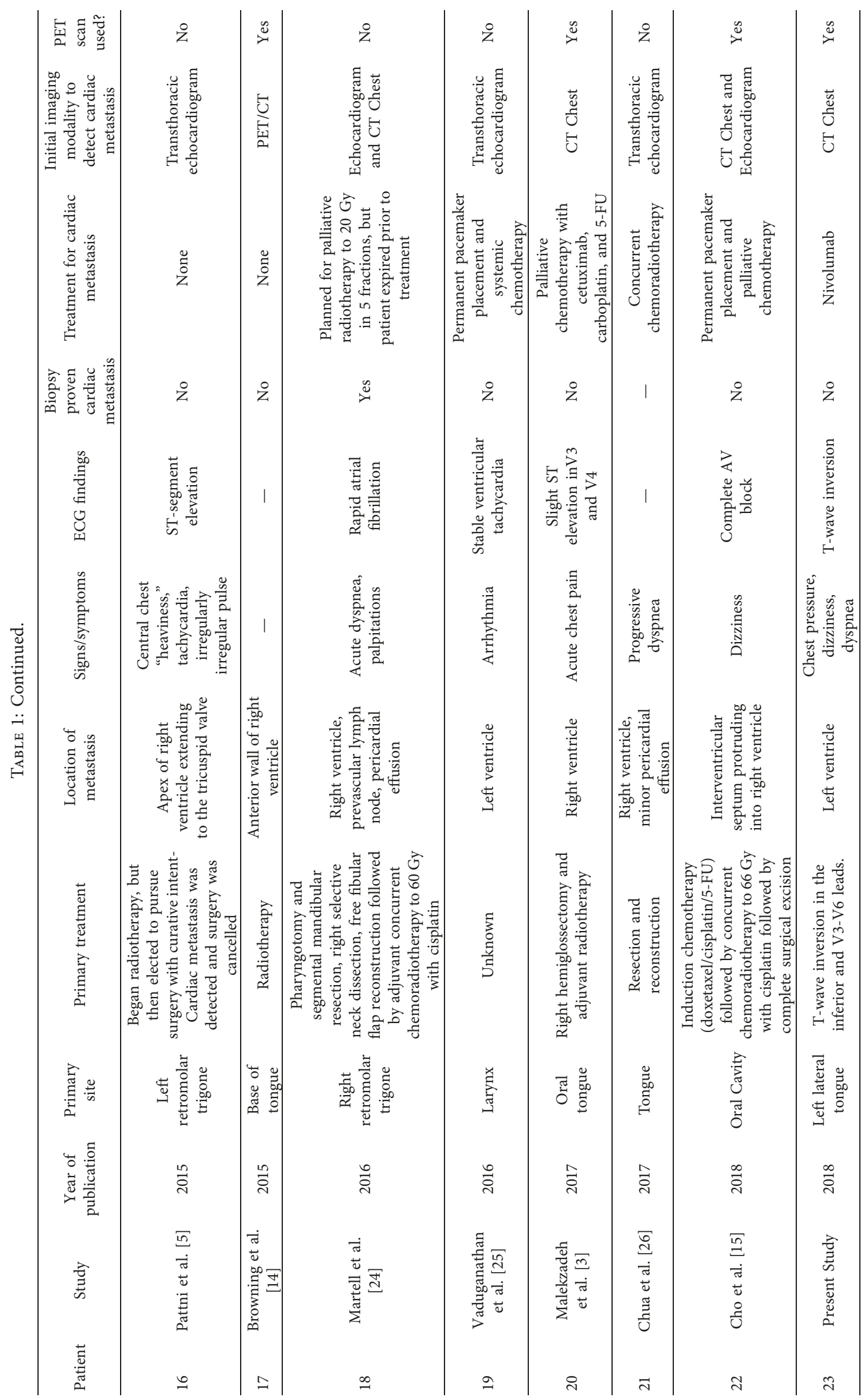


cisplatin-based chemotherapy and radiotherapy, but developed progression of disease and a new cardiac metastasis. In the current era, novel immunotherapeutic drugs, such as pembrolizumab or nivolumab (anti-PDL-1 antibodies), may have a significant impact on the survival outcomes of these patients [27-29]. Upon detection of the cardiac metastasis, the patient began treatment with nivolumab, which is approved for patients with recurrent and metastatic head and neck cancer that is refractory to cisplatin chemotherapy.

In conclusion, metastatic disease to the heart in oral cavity cancer is an uncommon finding, lacking optimal guidelines in terms of diagnosis and management. Diagnosis is quite challenging since cardiac metastases are often clinically silent, and there is no clear beneficial role of routine surveillance imaging. In symptomatic patients, a multimodality approach using imaging such as PET/CT, cardiac MRI, echocardiogram, and ECG findings should be used to confirm the location and extent of disease, which may help to guide treatment options.

\section{Conflicts of Interest}

The authors declare that there are no conflicts of interest regarding the publication of this paper.

\section{References}

[1] S. Nagata, K. Ota, M. Nagata, and M. Shinohara, "Cardiac metastasis of head and neck squamous cell carcinoma," International Journal of Oral and Maxillofacial Surgery, vol. 41, no. 12, pp. 1458-1462, 2012.

[2] R. Bussani, F. De-Giorgio, A. Abbate, and F. Silvestri, "Cardiac metastases," Journal of Clinical Pathology, vol. 60, no. 1, pp. 27-34, 2007.

[3] S. Malekzadeh, A. Platon, and P. A. Poletti, "Cardiac metastasis of tongue squamous cell carcinoma complicated by pulmonary embolism: a case report," Medicine, vol. 96, no. 28, article e7462, 2017.

[4] A. D. Puranik, N. C. Purandare, S. Sawant et al., "Asymptomatic myocardial metastasis from cancers of upper aerodigestive tract detected on FDG PET/CT: a series of 4 cases," Cancer Imaging, vol. 14, p. 16, 2014.

[5] N. Pattni, A. Rennie, T. Hall, and A. Norman, "Cardiac metastasis of oral squamous cell carcinoma," BMJ Case Report, vol. 2015, article bcr2015211275, 2015.

[6] C. Chiles, P. K. Woodard, F. R. Gutierrez, and K. M. Link, "Metastatic involvement of the heart and pericardium: CT and MR imaging," Radiographics, vol. 21, no. 2, pp. 439-449, 2001.

[7] N. Nomoto, T. Tani, T. Konda et al., "Primary and metastatic cardiac tumors: echocardiographic diagnosis, treatment and prognosis in a 15-years single center study," Journal of Cardiothoracic Surgery, vol. 12, no. 1, p. 103, 2017.

[8] T. Strecker, J. Rosch, M. Weyand, and A. Agaimy, "Primary and metastatic cardiac tumors: imaging characteristics, surgical treatment, and histopathological spectrum: a 10-yearexperience at a German heart center," Cardiovascular $\mathrm{Pa}$ thology, vol. 21, no. 5, pp. 436-443, 2012.

[9] S. Neragi-Miandoab, J. Kim, and G. J. Vlahakes, "Malignant tumours of the heart: a review of tumour type, diagnosis and therapy," Clinical Oncology, vol. 19, no. 10, pp. 748-756, 2007.

[10] C. F. Chen, O. Tsutsumi, T. Fujiwara, N. Mitsuhashi, and M. Mizuno, "Human chorionic gonadotropin levels in the follicular fluid in relation to oocyte maturity in in vitro fertilization," Nihon Sanka Fujinka Gakkai Zasshi, vol. 43, no. 7, pp. 789-790, 1991.

[11] Network NCC, "Head and neck cancers," 2018, https://www. nccn.org/professionals/physician_gls/pdf/head-and-neck.pdf.

[12] R. Rodel, H. J. Straehler-Pohl, H. Palmedo et al., "PET/CT imaging in head and neck tumors," Radiologe, vol. 44, no. 11, pp. 1055-1059, 2004.

[13] W. Zemann, M. Feichtinger, E. Kowatsch, M. Schanbacher, and H. Karcher, "Cardiac metastasis after squamous cell carcinoma of the oral cavity: case report," British Journal of Oral and Maxillofacial Surgery, vol. 45, no. 5, pp. 425-426, 2007.

[14] C. M. Browning, J. F. Craft, M. Renker, U. J. Schoepf, and S. Baumann, "Squamous cell carcinoma of the tongue with metastasis to the right ventricle," American Journal of the Medical Sciences, vol. 349, no. 5, pp. 461-462, 2015.

[15] J. Y. Cho, K. H. Kim, H. Park, H. J. Yoon, and J. C. Park, "Complete atrioventricular block as an initial manifestation of recurred oral cavity cancer: a case report," BMC Cardiovascular Disorders, vol. 18, no. 1, p. 142, 2018.

[16] N. U. Yadav, D. Gupta, M. S. Baum, N. Roistacher, and R. M. Steingart, "Cardiac metastases from head and neck cancer mimicking a myocardial infarction," Journal of Oral and Maxillofacial Surgery, vol. 72, no. 8, pp. 1627-1635, 2014.

[17] S. Gullulu, B. Ozdemir, T. Senturk, I. Baran, J. Cordan, and G. Filiz, "Cardiac metastasis in a laryngeal carcinoma and associated electrocardiographic changes," OtolaryngologyHead and Neck Surgery, vol. 135, no. 4, pp. 645-647, 2006.

[18] G. B. Werbel, J. H. Skom, D. Mehlman, and L. L. Michaelis, "Metastatic squamous cell carcinoma to the heart. Unusual cause of angina decubitus and cardiac murmur," Chest, vol. 88, no. 3, pp. 468-469, 1985.

[19] A. Rivkin, J. G. Meara, K. K. Li, C. Potter, and R. Wenokur, "Squamous cell metastasis from the tongue to the myocardium presenting as pericardial effusion," OtolaryngologyHead and Neck Surgery, vol. 120, no. 4, pp. 593-595, 1999.

[20] F. T. Schwender, I. Wollner, L. P. Kunju, R. E. Nakhleh, and K. M. Chan, "Squamous cell carcinoma of the buccal mucosa with metastases to the pericardial cavity, lung and thyroid," Oral Oncology, vol. 38, no. 1, pp. 114-116, 2002.

[21] S. Hans, D. Chauvet, B. Sadoughi, and D. F. Brasnu, "Cardiac metastasis after squamous cell carcinoma of the base of tongue," American Journal of Otolaryngology, vol. 30, no. 3, pp. 206-208, 2009.

[22] Y. T. Tsai, S. W. Kuo, and S. P. Hao, "Cardiac tamponade: a rare presentation from a rare metastatic site in oral squamous cell carcinoma," European Archives of Oto-Rhino-Laryngology, vol. 267, no. 9, pp. 1483-1485, 2010.

[23] J. Onwuchekwa and J. Banchs, "Early cardiac metastasis from squamous cell carcinoma of the tongue in 2 patients," Texas Heart Institute Journal, vol. 39, no. 4, pp. 565-567, 2012.

[24] K. Martell, R. Simpson, and D. Skarsgard, "Solitary myocardial metastasis from locoregionally controlled squamous cell carcinoma of the oral cavity," Cureus, vol. 8, no. 6, p. e650, 2016.

[25] M. Vaduganathan, N. K. Patel, S. A. Lubitz, T. G. Neilan, and D. M. Dudzinski, "A "Malignant” Arrhythmia: Cardiac Metastasis and Ventricular Tachycardia," Texas Heart Institute Journal, vol. 43, no. 6, pp. 558-559, 2016.

[26] S. Chua, W. H. Liu, and W. C. Lee, "Isolated huge right ventricular tumor: cardiac metastasis of tongue cancer," 
Korean Journal of Internal Medicine, vol. 32, no. 6, pp. 1119-1120, 2017.

[27] R. L. Ferris, G. Blumenschein Jr., J. Fayette et al., "Nivolumab for recurrent squamous-cell carcinoma of the head and neck," New England Journal of Medicine, vol. 375, no. 19, pp. 1856-1867, 2016.

[28] T. Y. Seiwert, B. Burtness, R. Mehra et al., "Safety and clinical activity of pembrolizumab for treatment of recurrent or metastatic squamous cell carcinoma of the head and neck (KEYNOTE-012): an open-label, multicentre, phase 1b trial," Lancet Oncology, vol. 17, no. 7, pp. 956-965, 2016.

[29] J. Bauml, T. Y. Seiwert, D. G. Pfister et al., "Pembrolizumab for platinum- and cetuximab-refractory head and neck cancer: results from a single-arm, phase II study," Journal of Clinical Oncology, vol. 35, no. 14, pp. 1542-1549, 2017. 


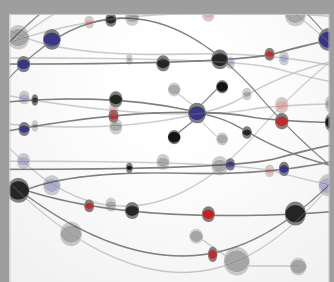

The Scientific World Journal
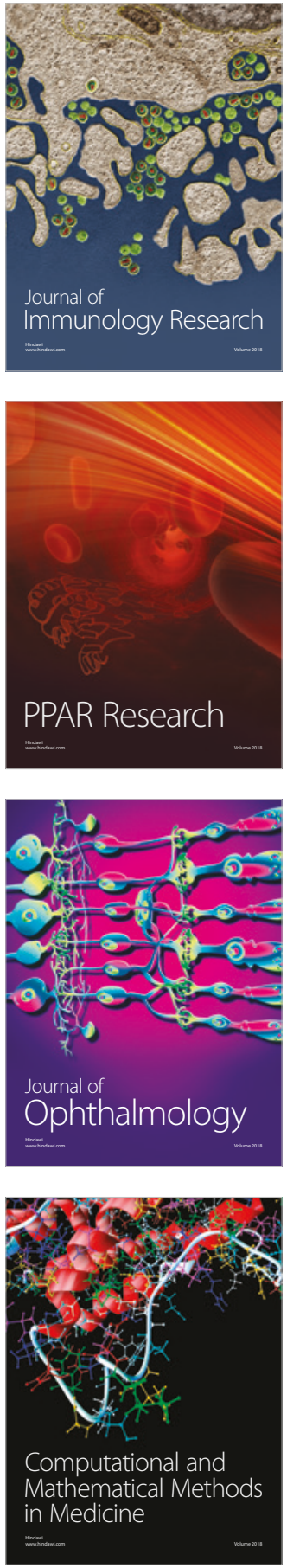

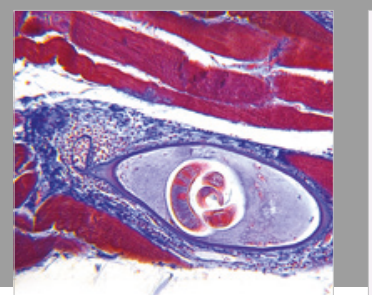

Gastroenterology Research and Practice

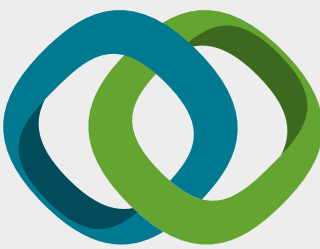

\section{Hindawi}

Submit your manuscripts at

www.hindawi.com
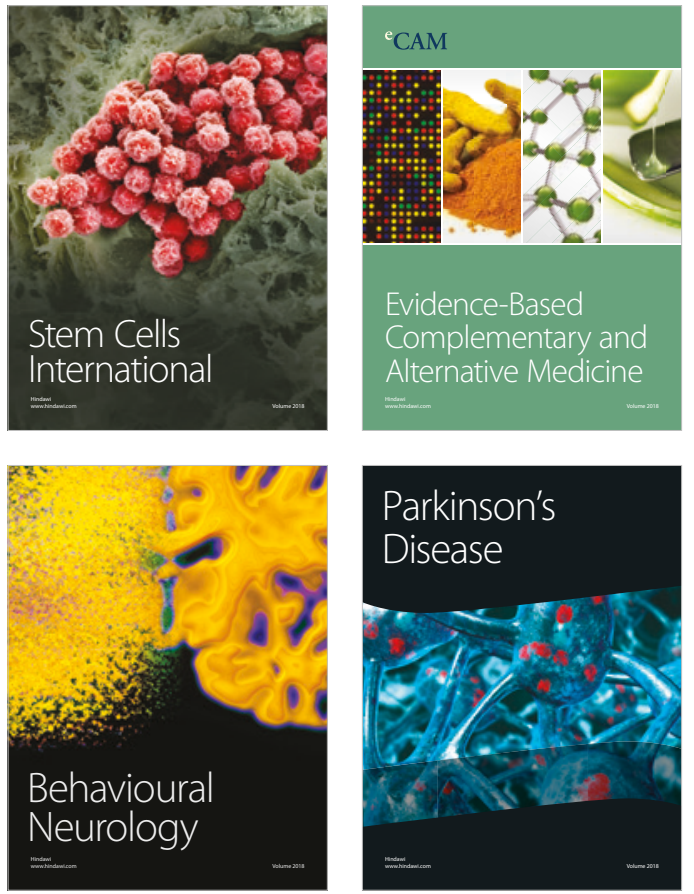

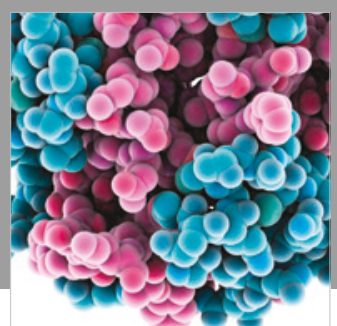

ournal of

Diabetes Research

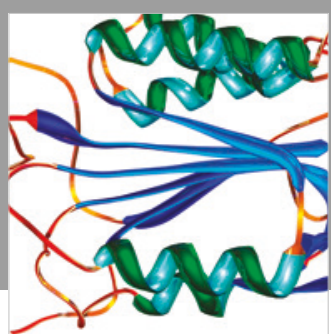

Disease Markers
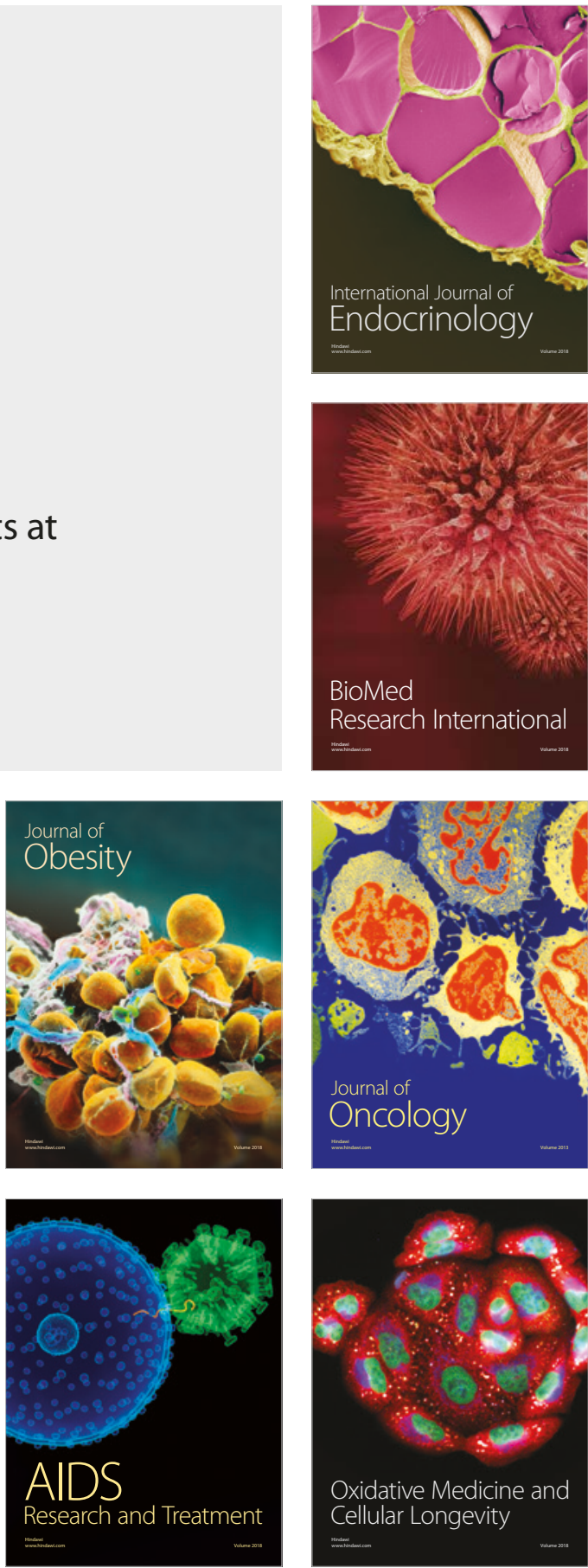